\title{
DIVERSIDAD Y MEJORAMIENTO DE LA CALIDAD EN EL MEDIO UNIVERSITARIO CHILENO
}

Orlando Poblete* 


\section{RESUMEN}

Una de las características del sistema de educación superior chileno es su diversidad. Ésta reviste variadas formas, desde las diferencias cronológicas de fundación de las instituciones a las que derivan de la naturaleza pública, privada o eclesiástica de sus titulares. En este texto se atiende a la existencia de universidades que presentan un ideario propio, haciendo ver su valor histórico y el aporte que representan a la diversidad del sistema. A continuación, se hace referencia a los mecanismos de acreditación, señalando su valor a la hora de asegurar la calidad de la educación superior.

\section{ABSTRACT}

Diversity is one of the characteristic features of the Chilean higher education system. The differences range from aspects such as when the universities were established to their public or ecclesiastical nature. This paper addresses the existence of universities that offer their own ideology, pointing out their historic value and the contribution that they make to the diversity of the system. The paper then refers to accreditation systems, calling attention to their value for assuring the quality of higher education. 


\section{DIVERSIDAD Y MEJORAMIENTO DE LA CALIDAD EN EL MEDIO UNIVERSITARIO CHILENO}

Un sistema diverso

Hoy ha llegado a ser un lugar común aludir a la enorme diversidad del sistema de educación superior chileno. Sin embargo, no resulta ocioso detenerse un momento para determinar los alcances de esa multiplicidad.

Un primer ámbito de diversidad está dado por la existencia no sólo de universidades, sino también de centros de formación técnica e institutos profesionales. Un error frecuente en nuestro medio es reflexionar sobre el sistema de educación superior teniendo en mente casi exclusivamente a las universidades, lo que conduce a graves distorsiones. Resulta muy difícil, cuando no imposible, explicar a un observador externo por qué en Chile sólo los alumnos de ciertas universidades pueden acceder a mecanismos de crédito preferencial y no, por ejemplo, las personas que estudian en un centro de formación técnica, en circunstancias de que, normalmente, pertenecen a un nivel socioeconómico más necesitado y cursan carreras que para el país son de enorme importancia en este momento. El hecho de que el peso político (mejor dicho, la menor capacidad de causar problemas políticos) de las instituciones no beneficiadas por esos mecanismos de financiamiento sea menor que el de las universidades no parece un argumento legitimo.

Otra manifestación de la diversidad se da en el orden geográfico y temporal. En Chile hay universidades desde el norte hasta el extremo 
más austral; hay algunas de tradición centenaria, como la Universidad de Chile, junto a otras novísimas, como esta Universidad de los Andes que recién cumple 15 años ${ }^{1}$.

Por último, hay formas muy variadas en cuanto a la propiedad: las hay del Estado, de la Iglesia Católica y otras de carácter privado, que a su vez revisten formas muy diversas. Es interesante hacer notar que estas últimas, aunque en Chile sean de reciente fundación, tienen una afinidad mucho mayor con lo que fue la universidad en sus inicios, allá en la Europa medieval. Por el contrario, la idea de que el Estado sea dueño y administre universidades es mucho más reciente, pues de manera general se remonta recién a Napoleón.

\section{Universidades con ideario}

Dentro del conjunto de los centros chilenos de educación superior hay algunos que tienen un ideario educativo explícito. Esto no debiera sorprender, pues así nacieron las universidades en el siglo XII y esa fue una de sus notas distintivas durante muchos siglos. Sin embargo, en nuestros días, gran parte de los centros académicos han elegido presentarse como neutrales. No cabe duda de que es esta una opción legítima, aunque no es tan claro que sea la mejor desde el punto de vista académico. Procuraré ilustrarlo con un caso. La neutralidad filosófica con la que se presentan nuestras universidades las ha llevado, por ejemplo, a excluir de sus planes de estudio la enseñanza de la teología. Las preguntas que surgen son la siguientes: ¿es esa una decisión filosóficamente neutral? ¿Cómo se puede justificar la exclusión del quehacer académico de la pregunta sobre Dios, que ha sido decisiva en la conformación de nuestra cultura? Alguien podría decir que esa es una pregunta privada, que no corresponde que sea respondida por las universidades. Sin embargo, la determinación de qué es privado y qué no lo es dista mucho de ser neutral (GarcíaHuidobro, 1999). Más bien es tributaria de una cierta filosofía liberal que puede ser buena o mala pero que nunca ha sido aséptica.

Lo que señalo no tiene que ver directamente con la aceptación o no del cristianismo. Desde mi campo académico, el del Derecho Procesal, podemos ver que en diversos procedimientos jurídicos de

1 Un panorama histórico en: Bravo Lira, Bernardino, La universidad en la historia de Chile, 1622-1992, Pehuén-Universidad Santo Tomás, Santiago de Chile, 1992. 
Roma los litigantes debían pronunciar juramentos ante la divinidad ${ }^{2}$. Es decir, las cuestiones religiosas estaban lejos de ser meramente privadas. No es otra la razón por la cual los primeros juristas que conocemos pertenecían al colegio sacerdotal de los pontífices, siendo ellos los que gozaban del monopolio de la interpretación del derecho en el sentido de escudriñar el alcance que debía darse a las prescripciones de la ley de las XII Tablas. Eran ellos, por otra parte, los que redactaban los formularios que permitían la aplicación del derecho a las más diversas situaciones, y los que conocían a fondo las formas en que debía desarrollarse un procedimiento válido (Magallón, 2000 , pp. 40 ss.). Más tarde, pese a la secularización de la jurisprudencia y del derecho en general, se mantienen algunos resabios de esta influencia religiosa, por ejemplo, en la pervivencia del juramento como medio probatorio en el proceso y en la autoridad de que gozan los juristas en la emisión de sus respuestas.

Además, diversas normas procesales que hoy conocemos tienen su origen y explicación, en buena medida, en viejas instituciones del Derecho Canónico. Es más, el arte mismo, la literatura y la arquitectura de Occidente permanecen incomprensibles para quien ignore los contenidos y la historia de las religiones y, más específicamente, del cristianismo.

Quiero mostrar con esto que, para el país, no es indiferente la existencia de universidades que hundan sus raíces en aquella centenaria tradición que afirma la posibilidad de hacer ciencia en diálogo con las cuestiones últimas de la existencia humana: las que plantea la religión. La idea cristiana de hombre ha sido la base para muchos de los mayores adelantos culturales de Occidente. Siguiendo en el campo jurídico, hay que reconocer que la entera teoría de los derechos humanos sería inconcebible sin la idea cristiana de la persona y su dignidad (Pereira,

2 En la misma génesis del proceso romano advertimos la importancia de la religio, por cuanto las dos primitivas formas de proceso, el sacramentum in rem y el sacramentum in personam de la primera época arcaica romana, a través de las cuales se persigue una cosa o una determinada conducta, respectivamente, finalizan con una resolución en la que el magistrado decide únicamente sobre la base del sacramentum u ofrenda que considere justo (vid. por todos, Guzmán, 1996, p.118). Por otra parte, en el desarrollo de la fase probatoria del proceso, la misma existencia del juramento (iusiurandum), en el que, faltando medios de prueba suficientes, puede el demandante apelar a la conciencia del demandado, reafirma el valor de lo religioso en el ámbito jurídico (vid. a este respecto, d' Ors, 1997, p. 146, n. 2). 
1987; Salinas, 1994). Como puede apreciarse, la cuestión no es menor. Aunque resulta posible que se planteen iniciativas universitarias de otra naturaleza, no parece razonable negar la legitimidad de proyectos que están en la base misma de nuestra cultura. Es más, cabe pensar que la diferencia no está entre universidades que tienen un ideario y otras que no lo tienen, sino, en muchos casos, entre algunas que lo hacen explícito y otras que, so pretexto de neutralidad, lo mantienen inconfesado o, al menos, inconsciente.

En los últimos años se ha afirmado que los fondos estatales sólo deben beneficiar a aquellas instituciones de educación superior que no tienen un ideario definido. Lo visto ayudará a entender que esa afirmación no está suficientemente justificada, al menos por tres razones. Primero, porque no es consciente de la cantidad de supuestos ideológicos -en el mejor sentido de la palabra- que se esconde detrás de ciertas propuestas académicas "neutrales". Segundo, porque introduce discriminaciones que difícilmente se pueden sustentar desde el punto de vista jurídico-constitucional. Y, tercero, porque olvida el hecho elemental de que los recursos del Estado no son más que medios que le han transferido los particulares y que buena parte de los ciudadanos tienen ideas y preferencias que no pueden ser desatendidas a la hora de asignar los fondos que administra. Las distinciones que se podrán hacer deberían depender de la calidad y no de criterios extra académicos.

\section{El mejoramiento de la calidad}

Si lo dicho hasta aquí resulta aceptable o, al menos, posible, entonces es necesario que los procedimientos de mejoramiento de la calidad sean capaces no sólo de respetar, sino también de fomentar esa legítima diversidad que se da en el sistema chileno de educación superior. Dicha variedad es un bien que hay que promover y no simplemente un mal menor que hay que tolerar en aras de la convivencia democrática. Así parece haberlo entendido el proyecto de ley que presentó el Gobierno sobre estas materias, sin perjuicio de las reformas que sea conveniente introducir para evitar que un excesivo peso estatal -del Gobierno de turno- pueda desequilibrar el sistema.

La acreditación institucional que ha propuesto la autoridad busca, en efecto, verificar que la misión de cada universidad no sea un mero 
enunciado teórico, sino que se manifieste en diversos campos, desde la forma en que se toman las decisiones hasta el tipo de mecanismos que se ponen en marcha para asegurar una cultura de la autoevaluación. Otro tanto habrá que decir de la futura acreditación de programas. Como en otras materias, siempre es bueno poner aquí un ejemplo. En los programas de doctorado que tradicionalmente se han llevado a cabo en Alemania y otros países de la Europa continental, el elemento decisivo es la tesis doctoral, y los cursos de doctorado, o no existen o tienen una importancia sólo menor. En los Estados Unidos de Norteamérica, en cambio, la formación doctoral consta, en buena medida, de cursos sistemáticos que deben ser seguidos y aprobados antes de llevar a cabo la investigación doctoral. Alguien podría preguntarse cuál es el sistema ideal para Chile. Me parece irrelevante, dado que, en ambos regímenes, se han formado académicos de gran jerarquía. Lo más razonable es que la acreditación de programas tenga la flexibilidad suficiente como para asegurar la calidad de programas que se orienten, según uno u otro modelo, sin imponer parámetros rígidos que menguarían la valiosa diversidad de la que venimos hablando.

Es más, dentro de cada uno de esos regímenes también cabe encontrar muchas posibilidades: ¿deben tener los cursos doctorales un carácter sistemático y general, o más bien un carácter monográfico, atendido que la formación de pregrado ya tiene un carácter general? Nuevamente, lo mejor es aquí la variedad, es decir, que cada universidad pueda elegir lo que le parece más apropiado, teniendo en cuenta, además, que no existe un sistema perfecto y que lo mejor para el país es que sus futuros académicos puedan elegir de acuerdo con sus preferencias y capacidades.

La diversidad de centros académicos lleva consigo el hecho de que las consecuencias académicas de los procesos de acreditación sean muy distintas en las distintas universidades. Veámoslo, por un momento, desde el punto de vista político. En algunas grandes universidades, donde las autoridades son generadas por votación de los distintos estamentos académicos, es posible que los intereses de los diversos grupos sean tan fuertes que el gobierno universitario no esté en condiciones de llevar a cabo reformas que son exigidas por el bien de toda la institución. Esto puede afectar notablemente la calidad 
de la educación. En este contexto, las recomendaciones que emanen de un proceso de acreditación pueden dar legitimidad y fuerza a esas medidas de reforma y, por tanto, hacerlas viables. Algo semejante puede suceder en aquellas universidades donde se da una tensión entre los dueños, que desean obtener un legítimo beneficio económico, y el estamento académico, que tiene requerimientos que no siempre se conjugan con los intereses de los propietarios. La acreditación, en ese contexto, tiene el mérito de arbitrar entre esas fuerzas y conducir hacia un sano equilibrio.

Pero las ventajas de un proceso de acreditación bien realizado no sólo son de índole política ni se limitan a cierto tipo de universidades. El desafío para el sistema chileno de educación superior es tomar la acreditación como una oportunidad única para fomentar en las distintas instituciones una cultura de la autoevaluación, que puede tener significativos resultados en el mejoramiento de la calidad, siempre que cada una de las partes involucradas la haga propia y no la entienda como una pesada tarea burocrática que se hace para satisfacer a unas autoridades gubernativas más o menos anónimas.

En definitiva, la acreditación no es el único mecanismo para mejorar nuestra tarea ni siquiera el principal, pero tiene el mérito de ayudarnos a saber quiénes somos. Y esa conciencia de la propia identidad es la clave para que la diversidad del sistema educacional no sea mera heterogeneidad, sino una realidad de gran riqueza, condición para un diálogo lleno de sentido.

Nota: El autor agradece las observaciones y sugerencias de la profesora María de los Ángeles Soza y del profesor Joaquín García-Huidobro. 


\section{REFERENCIAS BiBLIOGRÁFICAS}

Bravo Lira, Bernardino, La universidad en la historia de Chile, 16221992, Pehuén-Universidad Santo Tomás, Santiago de Chile, 1992.

D' Ors, Alvaro, Derecho Privado Romano, $9^{a}$ edición, EUNSA, Pamplona, 1997.

García-Huidobro, Joaquín, "Derechos humanos y liberalismo moral", en: Revista Chilena de Derecho 26 (1999), 475-487.

Guzmán, Alejandro, Derecho Privado Romano, Tomo I, Editorial Jurídica de Chile, Santiago de Chile, 1996.

Magallón, Jorge, La senda de la jurisprudencia romana, Ediciones Universidad Nacional Autónoma de México, México, 2000.

Pereira, Antonio-Carlos, Lecciones de Teoría Constitucional, Edesa, Madrid, 1987.

Salinas, Carlos, "El iusnaturalismo hispano-indiano y la protección jurídica de la persona", en: Anuario Mexicano de Historia del Derecho VI (1994), 219-237. 